\title{
Response to Comments on "Solubility and Dissolution Thermodynamic Data of Cefpiramide in Pure Solvents and Binary Solvents"
}

\author{
Fengxiang Tang ${ }^{1} \cdot$ Shan $\mathrm{Wu}^{1} \cdot$ Suying $\mathrm{Zhao}^{2}$
}

Published online: 24 January 2018

(C) Springer Science+Business Media, LLC, part of Springer Nature 2018

We greatly appreciate Prof. William E. Acree Jr. for his valuable comments on our recent paper entitled "Solubility and Dissolution Thermodynamic Data of Cefpiramide in Pure Solvents and Binary Solvents".

First, we need to make a correction to Eq. 15 in our published paper. Equation 15 should be represented as Eq. 1 here:

$$
\ln \left(x_{\mathrm{A}}\right)_{m, T}=A_{1}+A_{3} \ln T+A_{5} \frac{x_{\mathrm{B}}^{0}}{T}+A_{7} \frac{\left(x_{\mathrm{B}}^{0}\right)^{3}}{T}+A_{8} \frac{\left(x_{\mathrm{B}}^{0}\right)^{4}}{T} .
$$

The values of coefficients, $A_{1}, A_{3}, A_{5}, A_{7}$ and $A_{8}$, are shown in Table 1 . Just as Prof. William E. Acree Jr. suspected, the $A_{7}$ coefficient (in bold) should be negative. All the calculated solubilities of cefpiramide in binary ethanol + water solvent mixtures in Table 3 and Fig. 7 in the published paper were calculated according to Eq. 1.

Second, after we made a thorough investigation of the calculated solubility of cefpiramide in binary 2-propanol + water solvent mixtures, Eq. 16 in the published paper should be changed into Eq. 2 here:

$$
\ln \left(x_{\mathrm{A}}\right)_{m, T}=A_{1}+A_{3} \ln T+A_{5} \frac{x_{\mathrm{B}}^{0}}{T}+A_{6} \frac{\left(x_{\mathrm{B}}^{0}\right)^{2}}{T}+A_{7} \frac{\left(x_{\mathrm{B}}^{0}\right)^{3}}{T}+A_{8} \frac{\left(x_{\mathrm{B}}^{0}\right)^{4}}{T} .
$$

The corresponding values of coefficients, $A_{1}, A_{3}, A_{5}, A_{6}, A_{7}$ and $A_{8}$ (all in bold), are listed in Table 1. As compared with Eq. 16 in the published paper, the $A_{9} x_{\mathrm{B}}^{0} \ln T$ term is

This response refers to the commentary article at https://doi.org/10.1007/s10953-018-0714-3.

Fengxiang Tang

hellotfx@fzu.edu.cn

$\square$ Suying Zhao

zhaosuying@fzu.edu.cn

1 College of Chemistry, Fuzhou University, Fuzhou 350116, Fujian, China

2 College of Chemical Engineering, Fuzhou University, Fuzhou 350116, Fujian, China 
Table 1 Parameters of Eqs. 1 and 2 for cefpiramide in binary solvents mixtures

\begin{tabular}{|c|c|c|c|c|}
\hline \multirow[t]{2}{*}{ Parameters } & \multicolumn{2}{|l|}{ Ethanol + Water } & \multicolumn{2}{|c|}{ 2-Propanol + Water } \\
\hline & Parameter values & $P$ value & Parameter values & $P$ value \\
\hline$A_{1}$ & -93.252 & 0.0000 & - 97.089 & 0.0000 \\
\hline$A_{2}$ & - & - & - & - \\
\hline$A_{3}$ & 13.927 & 0.0000 & 14.607 & 0.0000 \\
\hline$A_{4}$ & - & - & - & - \\
\hline$A_{5}$ & 3559.445 & 0.0000 & 6564.039 & 0.0000 \\
\hline$A_{6}$ & - & - & $-18,344.960$ & 0.0000 \\
\hline$A_{7}$ & $-10,448.710$ & 0.0000 & $20,679.680$ & 0.0000 \\
\hline$A_{8}$ & 8314.726 & 0.0000 & - 8547.894 & 0.0000 \\
\hline$A_{9}$ & - & - & - & - \\
\hline$r$ & 0.991 & - & 0.994 & - \\
\hline 100MRD & 9.83 & - & 6.49 & - \\
\hline
\end{tabular}

$x_{\mathrm{B}}^{0}$ is from 0 to 0.9

removed because the significance level $\alpha$ we used in the curve-fit was 0.01 , not 0.05 as the published paper reported. Namely, only when the associated P-values were found to be less than 0.01 , were the corresponding items kept. In fact, all the calculated solubilities of cefpiramide in binary 2-propanol + water solvent mixtures listed in Table 4 and Fig. 8 in the published paper were calculated from Eq. 2 above.

Finally, we must apologize for the misunderstanding and errors we made and say thanks to Prof. William E. Acree Jr. again. 